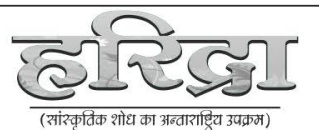

ISSN : 2582-9092

\title{
भासकृत रूपकों में वैदिक वामन-विष्णु तथा बलि आख्यान \\ एक अध्ययन
}

\section{अशु राधा}

वैदिक काल में हमारे ऋषियों ने वेदों के गूढ़तम रहस्य को समझाते हेतु अनेक रोचक प्रसंगों का वेदों में समावेश किया जिससे मानवीय चेतना को जाग्रत एवं प्रेरित किया जा सके और वेदों में निर्दिष्ट ज्ञान सरलता से प्राप्त हो सके। यही रोचक प्रसंग आख्यान से सम्बोधित किये गए। "चक्षिङ्'-व्यक्तायां वाचि, अयं दर्शने अपि" (स्पष्ट बोलना और देखना ) धातु से "आख्यान" पद की रचना हुई है। 'चक्षिड्' को "ख्यान" आदेश होकर यह 'ख्या' धातु का रूप धारण कर लेती है- "चक्षिड: ख्याज्।" "आ" उपसर्गपूर्वक "ख्या" धातु से "ल्युट्" (अन्) प्रत्यय के योग से "आख्यान" शब्द की निष्पत्ति हुई है। वैदिक वाड़्मय में कई प्रसंगों में "आख्यानम्", "आख्यायिका", "आख्यानविद्" शब्दों का प्रयोग किया गया है। ऐतरेय ब्राह्मण में शुनः शेप के प्रसंग में स्पष्टतः कहा गया है"शौन: शेपम् आख्यानम्।" शांखायन श्रोतसूत्र में भी कहा है-“"तदेतत् शौन: शेपम् आख्यानम्।" आपस्तम्ब श्रोतसूत्र मैं इसी आख्यान के साथ "शौनः शेपप् आख्यायते" कहकर आख्यायते क्रिया का प्रयोग है। इस क्रिया का प्रयोग जैमिनीय ब्राह्मण में भी हुआ है-"यौधाजयम् इत्याख्यायते।" "औशनम् इत्याख्यायते।"

वेदों में ऐसे अनेक प्रेरणादायी आख्यान उपलब्ध होते हैं जिनको आधार बनाकर लौकिक संस्कृत साहित्य के कवियों ने नूतन शिल्प निर्मित किये। इन काव्यों पर वैदिक आख्यान या पुराख्यान का प्रभाव तो देखा गया किन्तु मूल वैदिक आख्यानों को सम्पुष्ट, परिवर्तित एवं विकसित कर कवियों ने अपने ग्रन्थों का पूर्णतः नवीन सृजन किया। लौकिक संस्कृत साहित्य के कवियों ने वैदिक आख्यानों को ही नहीं अपितु पुराण, रामायण तथा महाभारत के पुराख्यानों को भी अपने काव्य का आधार बनाया है।

'पुराख्यान' शब्द सामान्यतः पुरा तथा आख्यान इन दो शब्दों से निर्मित है। 'पुरा' का अर्थ है प्राचीन तथा 'आख्यान' का अर्थ है- ज्ञानविशेष। आख्यान ऐसी विद्या है जिससे हमारे ऐतिहासिक, सामाजिक, राजनीतिक, धार्मिक, दार्शनिक जन-जीवन पर प्रकाश पड़ता है। इस प्रकार पुराख्यान से तात्पर्य प्राचीन वाङ्मय अथवा प्राचीन साहित्य से है, जो वैदिक साहित्य में वर्णित है। वैदिक आख्यान नीति, धर्म और सांस्कृतिक तथ्यों के प्रथम स्रोत हैं। इनकी रोचकता, सरसता, सरलता और विद्वता ने लौकिक संस्कृत साहित्यकारों को इतना प्रभावित किया कि वे अपने काव्यों का उपजीव्य आख्यानों से ही ग्रहण करने लगे। लौकिक संस्कृत साहित्य के आदि नाटककार महाकवि भास के तेरह रूपक प्राप्त होते हैं जो निम्न है- 1. प्रतिमानाटकम् 2. अभिशेकनाटकम् 3. मध्यमव्यायोगम्
4. पंचरात्रम्
5. दूतघटोत्कचम्
6. कर्णभारम्
7. दूतवाक्यम्
8. उरुभंगम्
9. बालचरितम
10. चारुदत्तम् 11. अविमारकम् 12. प्रतिज्ञायौगन्धरायणम् 13. स्वप्नवासवदत्तम्

प्रस्तुत षोध-पत्र "भासकृत रूपकों में वैदिक वामन-विष्णु तथा बलि आख्यान" को आधार बनाकर लिखा गया है। इस आख्यान में विष्णु द्वारा असुरों के संहार व वामनरूप धारण कर तीन पगों से तीनों लोकों को नापने की कथा का वर्णन है। ऋग्वेद में यह आख्यान इस प्रकार है-जब राजा बलि इन्द्रादि देवताओं का राज्य छीन लेते है; तव विष्णु ही वामन रूप में बलि का वध कर इन्द्र को राज्य वापिस दिला देते हैं- 


\section{“विष्णोर्न कं वीर्याणि प्रवोचं यः पार्थिवानि विममे रजांसि। यो अस्कभायदुत्तरं सद्यस्थं विचक्रमाणस्त्रेधा उरुगाय।।"}

इनके प्रमुख तीन पदों का तात्पर्य तीनों लोकों (पृथिवी, अन्तरिक्ष और आकाश) सहित सम्पूर्ण ब्रह्माण्ड् को व्याप्त करना है। शतपथ ब्राह्मण में उक्त आख्यान विस्तारपूर्वक प्राप्त होता है, जो इस प्रकार है- प्रजापति की दो संतान देव और असुरों में अपने महत्त्व के लिए लड़ाई हुई जिसमें असुर जीत गये। तब उन्होंने सोचा कि सम्पूर्ण संसार उनका ही हो गया। अब इसको आपस में ही बाँट लिया जाय। देवो को जब यह बात पता चली तो वे विष्णु (यज्ञ) को देवता बनाकर ले आये। देवों ने असुरों से कहा कि उनको भी पृथिवी का कुछ भाग मिले। इस पर असुरों ने देवों से कहा कि उनको उतना ही भाग मिलेगा, जितने में विष्णु लेट सकता है। देवताओं ने विष्णु (वामन) को लिटाकर तीन ओर से छन्द तथा पूर्व की ओर से अग्नि से घेर दिया। विष्णु यज्ञ है और यज्ञ समस्त पृथिवी पर व्याप्त है अतः सम्पूर्ण पृथिवी को देवों ने प्राप्त कर लिया। ऋग्वेद में इसका सन्दर्भ प्राप्त होता है। तैत्तिरीम संहिता में भी यह आख्यान प्राप्त होता है।

महाकवि भास ने भी भगवान विष्णु के वामनरूप की बारम्वार स्तुति की है जो इस प्रकार है-

\section{"अत्क्षिप्तां सानुकम्पं सलिलनिधिजलादेकदंष्ट्राग्र रूढाम्, आक्रान्तामाजिमध्ये निह्ततदितिसुतामेकपादावघूताम् ।"}

अर्थात भगवान ने जिस पृथिवी को दयापूर्वक समुद्र के जल से निकाला अपने दन्ताग्र पर रखा, जिस की रक्षा के लिए युद्ध में राक्षसों का संहार किया, जिसे वामनावतार में एक डेग से नापा, रामावतार में जिसका सप्रेम पालन किया, अपने वश में कर के जिसे चक्र से पाला, वही भगवान् यह एकातपत्र पृथिवी आपको प्रदान करे। और भी-

\section{"पायात्स वोऽसुररवधुह्टदयवसाद: पादो हरेः कुवलयामलखड्गनीलः}

\section{यः प्रोद्यतस्त्रिभुवनक्रमणे रराज वैदूर्यसंक्रम इवाम्बरसागरस्य।।"}

अर्थात्- हरि (विष्णु के वामनावतार) का वह पद आप लोगों (सहृदयों, सामाजिकों) की रक्षा करे; जो नील-कमल के समान स्वच्छ तथा तलवार के भाँति नीला है। वह त्रिभुवन को नापने के लिए उठाए जाने पर असुरों की (अथवा असुरराज बलि की) पत्नियों के विषय में विषाद उत्पन्न करने वाला है। तथा ऐसा शोभित को रहा है मानो आकाश के विस्तृत समुद्र से वैद्युमणि की राशि निकली हो या उस पर वैद्रू्यमाणि का कोई सेतु बाँधा गया हो।

तथापि-"त्रिचरणातिक्रान्तत्रिालोको नारायणः खल्वत्रभवान् | शरणं व्रजन्तु भवन्तः।"14 अर्थात इन्होंने तो तीन चरणों से सम्पूर्ण त्रिलोक को नाप लिया था अवश्य ही ये नारायण हैं। आप सब शरण में जायें। तथापि-

\section{"नारायणस्त्रिभुवनैकपरायणो वः पायादुपायशतयुक्तिकरः सुराणाम्। लोकत्रयाविरतनाटकतन्त्रवस्तु प्रस्तावनाप्रतिसमापनसुत्राधारः ।"}

अर्थात - तीनों लोकों में जो एकमात्र प्रधान-पुरुष देवताओं की विजय के लिए सैकडों उपाय करने वाला है तथा तीनों लोकों में अनवरत अभिनीत होने वाले नाटक की कथावस्तु, प्रस्तावना एवं समाप्ति का नियमन करने वाला सुत्रधार है, वह विष्णु आप लोगों की रक्षा करे। तथापि- "प्रभुरेव त्रैलोक्यनाथो भगवांश्चक्रायुधः" अर्थात भगवान चक्रपाणि तीनों लोकों के स्वामी प्रभु ही हैं। 
तथापि- "शखक्षीरवपु: पुरा कृतयुगे नाम्ना तु नारायणस्त्रेतायां त्रिपदार्पितत्रिभुवना विष्णुः सुवर्णप्रभः।" अर्थात पहले सतयुग में जो शंख और दूध के समान नारायण नाम से प्रसिद्ध थे, त्रेतायुग में कुन्दन की कान्ति वाले जिस विष्णु (वामन) ने तीन पादक्रमों (पगों) से तीनों लोकों को नाप लिया था, द्वापर में दूर्वा के समान श्यामल जिस रामचन्द्र ने रावण का वध किया और जो दामोदर कलियुग में अज्जन के समान कृश्ण शरीर वाले हैं वे सर्वदा तुम लोगों की रक्षा करें।

तथापि- "पुनः स्थापयितुं प्राप्ताविन्द्रं हरिहराविव।" अर्थात् राज्याच्युत इन्द्र को पुनः राज्य-स्थापित करने के लिये आये हुए विष्णु या शिव हों।

इस प्रकार कहा जा सकता है कि भास वर्णित विष्णु वामन तथा बलि आख्यान के स्वरूप का साम्य वैदिक विष्णु-वामन आख्यान से मिलता है। अतः प्रस्तुत आख्यानों का बीज वैदिक वाड़मय ही रहा है। महाकवि भास ने उस बीज स्वरूप आख्यान को कहीं यथावत रखा तो कहीं परवर्ती साहित्यिक कथा से समन्वित स्वरूप का उल्लेख किया।

संदर्भ:

1. अष्टाध्यायी-2/4/54)

2. "वाचस्पत्यम्" एवं "शब्दकल्पद्रुम" नामक बृहत् संस्कृत कोशों में आख्यान पद

3. ऐतरेय ब्राह्मण, $-7 / 18$

4. शांखायन, श्रोतसूत्र- $15 / 27$

5. आपस्तम्ब श्रोतसूत्र- $18 / 19$

6. जैमिनीय ब्राह्मण- $1 / 122$

7. वही, $1 / 27$

8. ऋग्वेद, $1 / 154 / 1$

9. "वामनो हि विष्णुरास" शत0 ब्रा0 $1 / 2 / 5 / 5 ; 1 / 2 / 5 / 1 ; 1 / 2 / 5 / 1-9$

10. ऋ0, $1 / 154 / 1-6 ; 1 / 155 / 4 ; 6 / 49 / 13 ; 7 / 100 / 4 ; 8 / 12 / 27 ; 29 / 7$

11. तैत्तिरीय, $2 / 1 / 31$

12. भासनाटकचक्रम,, अविमारकम्, $1 / 1$

13. भासनाटकचक्रम्, मध्यमव्यायोगम्, $1 / 1$

14. भासनाटकचक्रम्, दूतवाक्यम्, पृ० - 39

15. भासनाटकचक्रम्, दूतघटोत्कचम, $1 / 1$

16. भासनाटकचक्रम्, वही, पृ -35

17. भासनाटकचक्रम्, बालचरितम्, $1 / 1$

18. भासनाटकचक्रम्, अभिषेकनाटकम्, $1 / 3$ 